\title{
Kelimpahan dan Indeks Ekologis Perifiton di Sungai Bone Kabupaten Bone Bolango Gorontalo
}

\author{
Abundance and Ecological Index of Peryphyton in Bone River Bone Bolango in \\ Gorontalo Regency
}

\section{Segita Kono $^{1^{*}}$, Ayinda Kristi Tiopo ${ }^{1}$, Nuralim Pasisingi ${ }^{1}$, Miftahul Khair Kadim $^{1}$}

\author{
${ }^{1}$ Jurusan Manajemen Sumberdaya Perairan, Fakultas Perikanan dan Ilmu Kelautan, UNG, \\ Gorontalo, 96111, Indonesia \\ *Korespondensi: segitak99@gmail.com
}

\begin{abstract}
ABSTRAK
Perifiton merupakan organisme yang hidup menempel pada substrat alam iseperti batu. Tujuan dari penelitian ini yaitu untuk mengetahui kelimpahan dan indeks ekologis perifiton di Sungai Bone Kabupaten Bone Bolango. Penelitian ini dilakukan di dua stasiun yakni di Desa Panggulo Kecamatan Suwawa Timur dan Desa Tolomato Kecamatan Suwawa Tengah Kabupaten Bone Bolango. Hasil penelitian menunjukkan bahwa di Sungai Bone ditemukan 23 genus yang terdiri dari 8 kelas. Kelimpahan relatif perifiton yang tertinggi yaitu dari kelas Bacillariophyceae sebesar 33\%. Indeks keanekaragaman perifiton di Stasiun 1 berkisar 1,80-1,90 dan pada Stasiun 2 berkisar 1,81-1,99. Indeks keseragaman perifiton di Stasiun 1 berkisar 0,70-0,75 dan di Stasiun 2 berkisar 0,86-0,93. Indeks dominansi hampir tidak ada individu yang mendominasi.
\end{abstract}

Kata kunci: Perifiton; kelimpahan; keanekaragaman; keseragaman; dominansi

\begin{abstract}
Periphyton is an organism that lives attached to natural substrates such as rocks. The purpose of this study was to determine the abundance, abundance and ecological index of periphyton in Bone River Bone Bolango in Gorontalo Regency. This research was conducted in two stations, namely Panggulo Village, East Suwawa District and Tolomato Village, Suwawa Tengah District, Bone Bolango Regency. The results showed that in the Bone River there were 23 genera consisting of 8 classes. The highest relative abundance of periphyton was from the class Bacillariophyceaeby $33 \%$. The periphyton diversity index at Station 1 ranges from 1,80 to 1,90 and at Station 2 ranges from 1,81 to 1,99. The periphyton uniformity index at Station 1 ranges from 0,70 to 0,75 and at Station 2 ranges from 0,86 to 0,93 . The dominance index is almost no individual who dominates.
\end{abstract}

Keywords: Periphyton; abundance; diversity; uniformity; dominance

\section{PENDAHULUAN}

Ekosistem perairan meliputi ekosistem air tawar dan ekosistem air laut. Ekosistem air tawar secara umum dibagi menjadi 2 yaitu perairan lentik (perairan tenang) misalnya danau, rawa, waduk dan sebagainya serta perairan lotik (perairan berarus) misalnya sungai
(Rafi'i dan Maulana, 2018). Sistem lentik adalah suatu perairan yang dicirikan air yang menggenang atau tidak ada aliran air, sedangkan sistem lotik adalah suatu perairan yang dicirikan oleh adanya aliran air yang cukup kuat, sehingga digolongkan 
kedalam perairan mengalir (Wahyuni dan Rosanti, 2016).

Sungai merupakan aliran air yang besar dan memanjang yang mengalir secara terus menerus dari hulu menuju hilir (Agustin et al., 2019). Kondisi sungai digambarkan sebagai badan air yang umumnya dangkal, arus biasanya searah, dasar sungai berupa batu kerikil dan berpasir, ada endapan atau erosi, temperatur air berfluktuasi, atas bawah hampir seragam (Dimenta et al., 2020). Lingkungan perairan sungai terdiri dari komponen abiotik dan biotik yang saling berinteraksi melalui arus energi dan daur hara (Isti'anah et al., 2015). Sungai memiliki fungsi sebagai tempat hidup organisme (Nangin et al., 2015) dan berperan penting dalam menunjang kegiatan dan kehidupan manusia (Pasisingi et al., 2014b). Banyak akti-vitas manusia baik itu di daerah pedesa-an maupun dilingkungan perkotaan yang tidak luput dari pemanfaatan air sungai (Kadim, 2014). Salah satu organisme yang hidup dan dapat beradaptasi dengan baik di sungai adalah perifiton.

Perifiton merupakan sekelompok organisme (mikroskopis) yang hidup menempel pada benda atau pada permukaan tumbuhan air yang terendam, tidak menembus substrat, diam atau bergerak (Yuniarno et al., 2015). Perifiton tersebut hidup dan menempel pada permukaan benda-benda di perairan, seperti batu, kayu, dan permukaan tumbuhan (Ameilda et al., 2016). Perifiton yang tumbuh pada batu disebut dengan Epilithic (Mardana, 2019).

Perifiton dapat berupa hewan atau tumbuhan. Perifiton yang berjenis hewan umumnya terdiri dari protozoa dan rotifera, sedangkan perifiton yang berjenis tumbuhan terdiri dari mikroalga (Ameilda et al., 2016). Diatom menjadi salah satu kelompok mikroalga yang digunakan sebagai biondikator perairan (Pasisingi, 2014), khususnya sungai (Pasisingi et al., 2014a) karena mampu menunjukkan respon yang cepat terhadap perubahan kondisi fisika dan kimia lingkungan perairan (Nogueira 2000; Yerli et al; 2012 dalam Pasisingi, 2014).

Keberadaan perifiton dalam satu perairan dengan perairan lainnya tidaklah sama. Beberapa faktor yang mempengaruhi keadaan perifiton dalam suatu perairan adalah kondisi fisik, kimiawi, dan biologi perairan (Yuniarno et al., 2015). Faktor-faktor tersebut, antara lain adalah suhu, arus, kekeruhan, unsur hara (nitrat, amonium, dan ortofosfat), oksigen, $\mathrm{pH}$, gas-gas terla-rut, dan adanya interaksi dengan organisme lain (Pratiwi et al., 2017). Kondisi kualitas air suatu perairan yang baik sangat penting untuk mendukung kelulushidupan organisme yang hidup di dalamnya (Kadim et al., 2017). Komunitas perifiton memiliki peran sebagai produsen dalam ekosistem air tawar dan mampu merekam perubahan kondisi kualitas perairan, sehingga dapat digunakan sebagai sistem peringatan dini tentang perubahan lingkungan serta keberadaan keanekaragaman hayati (Suryono dan Sudarso, 2019). Keseimbangan ekosistem yang terpelihara dengan baik memberikan daur ulang ekosistem air berlangsung secara alamiah (Kadim dan Pasisingi, 2018).

Tujuan dari penelitian ini yaitu untuk mengetahui kelimpahan, keanekaragaman, keseragaman, dan dominansi perifiton di Sungai Bone Kabupaten Bone Bolango.

\section{METODE PENELITIAN}

Penelitian ini dilaksanakan pada bulan November 2020 di perairan Sungai Bone, kemudian dilanjutkan dengan identifikasi sampel perifiton dilaksanakan di Laboratorium Hidrobioteknologi dan Biometrik Perikanan, Fakultas Perikanan dan Ilmu Kelautan, Universitas Negeri Gorontalo. 


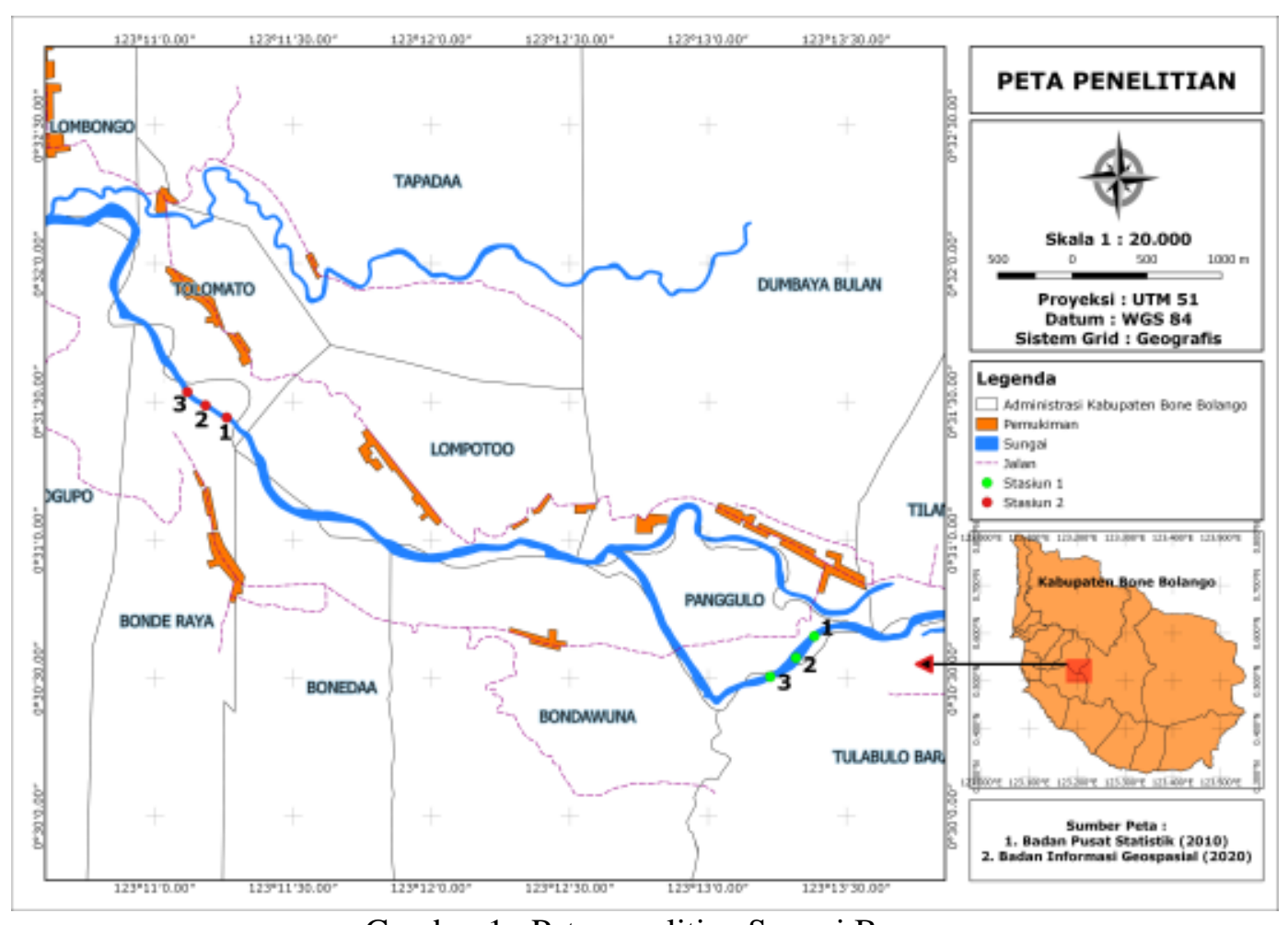

Gambar 1. Peta penelitian Sungai Bone

\section{Bahan}

Adapun bahan yang digunakan dalam penelitian ini adalah aquades, lugol $1 \%$, tisu basah dan tisu kering serta Pengambilan sampel perifiton dilakukan pada tiga titik di setiap stasiun. Perifiton yang diambil yang menempel pada substrat batu. Pengambilan sampel dilakukan secara acak sebanyak tiga substrat batu kemudian dilakukan pengerikan menggunakan sikat gigi halus terhadap permukaan substrat seluas $2 \times 2 \mathrm{~cm}^{2}$ dan $4 \times 4 \mathrm{~cm}^{2}$. Batu yang diambil merupakan batu yang terendam dan terkena paparan sinar matahari.

\section{Alat}

Alat yang digunakan dalam penelitian ini adalah meteran, sikat halus, bingkai ukuran, botol sampel, pipet tetes, kertas label, mikroskop, cover glass, alat tulis, GPS essential, kamera dan buku identifikasi mikroalga Davis (1955), Prescott (1970) dan Mizuno (1979).

\section{Analisis Data}

Analisis data dilakukan dengan cara penghitungan kelimpahan spesies, indek skeanekaragaman, indeks keseragaman dan dominansi dengan formula sebagai berikut:

\section{Kelimpahan Relatif (KR)}

Kelimpahan dihitung dengan menggunakan rumus (Odum, 1993 dalam Kusumaningsari et al., 2015) yaitu:

Keterangan:

$$
K R=\frac{n i}{N} \times 100 \%
$$

$\mathrm{KR}=$ Kelimpahan relatif

$\mathrm{ni}=$ Jumlah individu spesies ke- $\mathrm{i}$

$\mathrm{N}=$ Jumlah individu seluruh spesies

\section{Indeks Keanekaragaman (H')}

$$
H^{\prime}=-\sum_{i=0}^{n} p i \ln p i
$$


Keterangan:

$\mathrm{H}^{\prime}=$ Indeks keanekaragaman Shannon-Wiever $\left(\mathrm{H}^{\prime}\right)$

$\mathrm{Pi}=\mathrm{ni} / \mathrm{N}$

$\mathrm{ni}=$ Jumlah individu jenis ke- $\mathrm{i}$

$\mathrm{N}$ = Jumlah total individu semua jenis

Menurut Brower et al., (1990) dalam Agustin et al., (2019) nilai indeks keanekaragaman dapat diklasifikasikan dalam tiga kategori yaitu:

$0<\mathrm{H}^{\prime}<2,3$ : Keanekaragaman dan penyebaran jumlah individu pada setiap genus perifiton rendah, kestabilan komunitas perifiton rendah;

$2,3<\mathrm{H}^{\prime}<6,9$ : Keanekaragaman dan penyebaran jumlah individu setiap genus perifiton sedang, kestabilan komunitas perifiton sedang.

H'>6,9: Keanekaragaman dan penyebaran jumlah individu setiap genus perifiton tinggi, kestabilan komunitas perifiton tinggi.

\section{Indeks Keseragaman (E)}

$$
E=\frac{H^{\prime}}{H_{\text {maks }}}
$$

Keterangan:

$$
\begin{array}{ll}
\mathrm{E} & =\text { Indeks keseragaman } \\
\mathrm{H}^{\prime} & =\text { Indeks keanekaragaman } \\
\mathrm{H}_{\text {maks }} & =\ln \mathrm{S} \\
\mathrm{S} & =\text { Jumlah spesies }
\end{array}
$$

Menurut (Meiriyani et al., 2011) kisaran nilai indeks keseragaman dapat diklasifikasikan sebagai berikut:

$0<E<0,4$ : Keseragaman jenis rendah.

$0,4 \leq \mathrm{E} \leq 0,6$ : Keseragaman jenis sedang;

$0,6<\mathrm{E}<1$ : Keseragaman jenis tinggi.

\section{Indeks Dominansi (C)}

$$
C=\sum(P i)^{2}
$$

Keterangan:

$$
\begin{array}{ll}
\mathrm{Pi} & =\text { ni/N } \\
\mathrm{ni} & =\text { Jumlah individu genus ke-i } \\
\mathrm{N} & =\text { Jumlah total individu }
\end{array}
$$

Menurut Odum (1993) dalam Agustin et al., 2019) apabila nilai C mendekati 0 hampir tidak ada individu yang mendominansi dan biasanya diikuti nilai $\mathrm{E}$ yang besar (mendekati 1), sedangkan apabila nilai $\mathrm{C}$ mendekati 1 berarti terjadi dominansi jenis tertentu.

\section{HASIL DAN PEMBAHASAN}

Sungai Bone merupakan sungai terbesar di antara sungai-sungai di Gorontalo. Sungai Bone mempunyai panjang $119,13 \mathrm{~km}$, yang melintasi Kabupaten Bone Bolango, Kota Gorontalo dan bermuara ke Teluk Tomini.

Secara umum, perifiton yang ditemukan di Sungai Bone selama penelitian ada 23 genus yang terdiri dari 8 kelas sebagaimana disajikan pada Tabel 1.

Perifiton yang ditemukan, sebagian besar terdiri dari kelas Bacillariophyceae dari ordo Pennales. Hal ini karena kelas Bacillariophyceae mampu beradaptasi dengan lingkungan hidupnya dalam suatu perairan. Hal ini juga didukung oleh (Nasria et al., 2016) yang menunjukan bahwa kelas Bacillariophyceae memiliki penyebaran yang luas di perairan mengalir dan tingginya kelas ini disebabkan oleh kecocokan habitat dan kemampuan untuk beradaptasi dengan lingkungan yang ditempatinya.

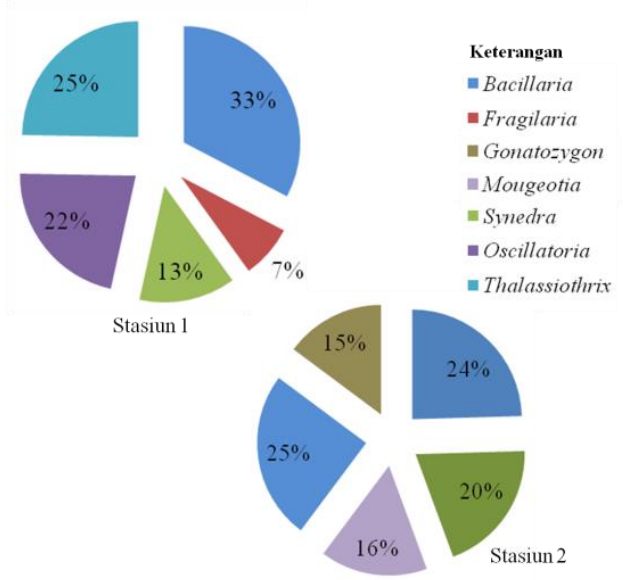

Gambar 2. Kelimpahan Perifiton pada Stasiun 1 dan Stasiun 2. 
Berdasarkan data pada Gambar 2 dapat dilihat bahwa kelimpahan perifiton yang tinggi pada Stasiun 1 dimiliki oleh genus Bacillaria (33\%), Thalassiothrix (25\%), Oscillatoria (22\%), Synedra (13\%) dan Fragilaria (7\%). Genus Bacillaria diduga yang termasuk dalam kelas ini mempunyai adaptasi yang tinggi dan ketahanan hidup pada berbagai kondisi perairan. Seperti pernyataan dari Nirmalasari, (2018) keberadaanya tertinggi diduga karena jenis ini bersifat kosmopolit dan penyebarannya luas serta memiliki tingkat toleransi yang tinggi terhadap perubahan faktor lingkungan.

Tabel 1. Jenis-jenis Perifiton di Sungai Bone Kabupaten Bone Bolango Gorontalo

\begin{tabular}{|c|c|c|}
\hline No & Kelas & Genus \\
\hline \multirow{13}{*}{1} & \multirow{13}{*}{ Bacillariophyceae } & Amphipleura \\
\hline & & Asterionella \\
\hline & & Bacillaria \\
\hline & & Cerataulina \\
\hline & & Eunotia \\
\hline & & Fragilaria \\
\hline & & Melosira \\
\hline & & Nitzschia \\
\hline & & Peronia \\
\hline & & Pinnularia \\
\hline & & Synedra \\
\hline & & Tabellaria \\
\hline & & Thalassiothrix \\
\hline 2 & Charophyceae & Penium \\
\hline \multirow{2}{*}{3} & \multirow{2}{*}{ Chlorophyceae } & Ankistrodesmus \\
\hline & & Microspora \\
\hline \multirow{2}{*}{4} & \multirow{2}{*}{ Chyanophyceae } & Oscillatoria \\
\hline & & Phormidium \\
\hline 5 & Conjugatophyceae & Mougeotia \\
\hline 6 & Coscinodiscophyceae & Rhizosolenia \\
\hline 7 & Oligotrichea & Eutintinnus \\
\hline \multirow{2}{*}{8} & \multirow{2}{*}{ Zygnematophyceae } & Closterium \\
\hline & & Gonatozygon \\
\hline
\end{tabular}

Tabel 2. IndeksKeanekargaman (H'), Keseragaman (E) dan Dominansi (C)

\begin{tabular}{ccccc}
\hline STASIUN & TITIK & $\mathbf{H}^{\prime}$ & $\mathbf{C}$ & $\mathbf{E}$ \\
\hline \multirow{3}{*}{1} & 1 & 1,90 & 0,22 & 0,70 \\
& 2 & 1,86 & 0,25 & 0,75 \\
& 3 & 1,80 & 0,24 & 0,73 \\
\hline \multirow{2}{*}{2} & 4 & 1,99 & 0,17 & 0,86 \\
& 5 & 1,81 & 0,18 & 0,93 \\
& 6 & 1,98 & 0,17 & 0,90 \\
\hline
\end{tabular}


Stasiusn 2 memiliki kelimpahan perifiton yang tinggi yaitu pada genus Thalassiothrix (25\%), Bacillaria (24\%), Synedra (20\%), Mougeotia (16\%), dan Gonatozygon (15\%). Jenis yang melimpah mampu bertahan dalam kondisi apapun yang jika dilihat sebagian besar perifiton tersebut masih bagian dari kelas Bacillariophyceae. Merujuk dari sumber Andriansyah et al., (2014) bahwa kelas Bacillariophyceae ditemukan dalam jumlah lebih banyak karena komunitas ini memiliki kemampuan menempel pada substrat dan dapat beradaptasi terhadap arus yang kuat sampai lambat.

Struktur komunitas perifiton sungai Bone Kabupaten Bone Bolango Gorontalo disajikan pada Tabel 1 . Indeks keanekaragaman ( $\left.H^{\prime}\right)$ perifiton tertinggi terdapat pada Stasiun 2 berkisar antara 1,81-1,99. Berdasarkan kisaran tersebut, Indeks keanekaragaman pada kedua lokasi pengamatan tersebut relatif hampir sama, dengan tingkat keanekaragaman rendah. Hal ini dinyatakan oleh Brower dkk. (1990) dalam Agustin et al., (2019) bahwa nilai indeks keanekaragaman $0<\mathrm{H}^{\prime}<2,3$ tergolong rendah. Semakin rendah kondisi lingkungan perairan, maka nilai indeks kenakeragaman jenis akan menurun seiring dengan menurunnya kondisi atau kualitas lingkungan perairan. Berdasarkan pernyataan Pratiwi et al., (2017) bahwa keadaan alam seperti masukan cahaya dan kecepatan arus dapat mempengaruhi keberadaan organisme serta kadar nutrien, pH, dan suhu (Zuardi dan Wardhana, 2018).

Menurut) Clark (1974) dalam Ulum et al., (2012) menyatakan keanekaragaman menggambarkan variasi spesies yang berada dalam suatu ekosistem, jika suatu ekosistem memiliki indeks keanekaragaman yang rendah mengindikasikan ekosistem tersebut dalam keadaan tertekan atau terdegradasi. Sebaliknya, ketika suatu ekosistem memiliki keanekaragaman yang tinggi maka ekosistem tersebut cenderung seimbang.
Indeks keseragaman (E) perifiton di Sungai Bone di Stasiun 1 berkisar antara 0,70-0,75 dan di Stasiun 2 berkisar antara 0,86-0,93. Berdasarkan kisaran tersebut, dapat dikategorikan keseragaman organisme dalam keadaan tinggi. Hal ini sesuai dengan Meiriyani et al., (2011) bahwa nilai indeks keseragaman $0,6>\mathrm{E}>1$ termasuk dalam keseragaman tinggi.

Menurut Widodo (1997) dalam Suryono dan Sudarso (2019) bahwa faktor yang mempengaruhi keseragaman diantaranya pencemaran kimia dan organik, perusakan habitat alami seperti pengonversian lahan menjadi peruntukan lain, serta perubahan iklim.

Secara keseluruhan, indeks dominansi rata-rata di 6 titik pengambilan sampel berada pada kategori sebesar 0,21. Hal ini berarti komunitas perifiton yang ada di perairan Sungai Bone tidak ada yang mendominasi. Hal ini didukung oleh Odum (1993) dalam Agustin et al., (2019) dimana nilai C mendekati 0 hampir tidak ada individu yang mendominansi.

\section{KESIMPULAN}

Hasil penelitian yang dilakukan di Sungai Bone ditemukan 23 genus yang terdiri dari 8 kelas yaitu kelas Bacillariophyceae (12 genus), kelas Charophyceae (1 genus), Chlorophyceae (2 genus), kelas Chyanophyceae (3 genus), kelas Conjugatophyceae (1 genus), kelas Coscinodiscophyceae (1 genus), kelas Oligotrichea (1 genus), dan kelas Zygnematophyceae (2 genus). Kelimpahan perifiton yang tertinggi yaitu dari kelas Bacillariophyceae sebesar 33\%. Indeks keanekaragaman perifiton di Sungai Bone termasuk kedalam kategori rendah, dan untuk indeks keseragaman perifiton termasuk kategori tinggi sedangkan untuk indeks dominansi hampir tidak ada individu yang mendominasi. 


\section{UCAPAN TERIMA KASIH}

Penulis mengucapkan terimakasih kepada staf Laboratorium Hidrobioteknologi dan Biometrik Perikanan, Fakultas Perikanan dan Ilmu Kelautan, Universitas Negeri Gorontalo atas peminjaman ruangan Laboratorium.

\section{DAFTAR PUSTAKA}

Agustin, A.D., Solichin, A., dan Rahman, A. (2019). Analisis Kesuburan Perairan Berdasarkan Kepadatan dan Jenis Perifiton di Sungai Jabungan, Banyumanik, Semarang. Journal of Maquares, 8(3), 185-192. https://doi.org/10.14710/marj.v8i3. 24254

Ameilda, C.H., Dewiyanti, I., dan Octavina, C. (2016). Struktur Komunitas Perifiton pada Makroalga Ulva lactuca di Perairan Pantai Ulee Lheue, Banda Aceh. Jurnal Ilmiah Mahasiswa Kelautan dan Perikanan Unsyiah, 1(3), 337-347.

Andriansyah, Setyawati, T.R., dan Lovadi, I. (2014). Kualitas Perairan Kanal Sungai Jawi dan Sungai Raya dalam Kota Pontianak Ditinjau dari Struktur Komunitas Mikroalga Perifitik. Jurnal Protobiont, 3(1), 61-70. https://doi.org/http://dx.doi.org/10. 26418/protobiont.v3i1.4583

Davis CC. (1955). The Marine and Freshwater Plankton. Michigan (US): Michigan State University Press.

Dimenta, R.H., Agustina, R., Machrizal, R., dan Khairul. (2020). Kualitas Sungai Bilah Berdasarkan Biodiversitas Fitoplankton Kabupaten Labuhanbatu, Sumatera Utara. Jurnal Ilmu Alam dan Lingkungan, 11(2), 24-33. https://doi.org/10.20956/jal.v11i2.1 0183
Isti'anah, D., Huda, M.F., dan Laily, A. N. (2015). Synedra sp. sebagai Mikroalga yang Ditemukan di Sungai Besuki Porong Sidoarjo, Jawa Timur. Bioedukasi: Jurnal Pendidikan Biologi, 8(1), 57-59. https://doi.org/10.20961/bioedukas i-uns.v8i1.3500

Kadim, M.K. (2014). Zonasi Sungai Umbulrejo di Kecamatan Dampit Kabupaten Malang Berdasarkan Komunitas Makrozoobentos. Nikè: Jurnal Ilmiah Perikanan dan Kelautan, 2(2), 56-59. https://doi.org/10.37905/.v2i2.1253

Kadim, M.K., dan Pasisingi, N. (2018). Status Mutu Perairan Teluk Gorontalo dengan Menggunakan Metode Pollution Index. Journal of Fisheries and Marine Research, 2(1), 1-8. http://dx.doi.org/10.21776/ube.jfmr .2018 .002 .01 .1

Kadim, M.K., Pasisingi, N., dan Paramata, A.R. (2017). Kajian Kualitas Perairan Teluk Gorontalo dengan Menggunakan Metode STORET. Depik Jurnal Ilmu-Ilmu Perairan, Pesisir dan Perikanan, 6(3), 235-241. https://doi.org/10.13170/depik.6.3. 8442

Kusumaningsari, S.D., Hendrarto, B., dan Ruswahyuni. (2015). Kelimpahan Hewan Makrobentos pada Dua Umur Tanam Rhizophora sp di Kelurahan Mangunharjo, Semarang. Diponegoro Journal of Maquares, 4(2), $58-$ 64.https://doi.org/10.14710/marj.v $4 \mathrm{i} 2.8528$

Mardana, M. A. (2019). Keanekaragaman Jenis Perifiton pada Eceng Gondok (Eichornia crassipes) di Danau Lut Tawar Kabupaten Aceh Tengah sebagai 
Referensi Mata Kuliah Limnologi [skripsi]. Universitas Islam Negeri Ar-Raniry.

Meiriyani, F., Ulqodri, T.Z., dan Putri W.A.E. (2011). Komposisi dan Sebaran Fitoplankton di Perairan Muara Sungai Way Belau Bandar Lampung. Maspari Journal, 3(2), 69-

77.https://doi.org/10.36706/maspar i.v3i2.1321

Mizuno T. (1979). Illustrations of the Freshwater Plankton of Japan. Osaka (JP): Hoikusha Publishing Co Ltd.

Nangin, S.R., Langoy, M.L., dan Katili, D.Y. (2015). Makrozoobentos Sebagai Indikator Biologis dalam Menentukan Kualitas Air Sungai Suhuyon Sulawesi Utara. Jurnal MIPA UNSTRAT, 4(2), 165-168. https://doi.org/10.35799/jm.4.2.20 15.9515

Nasria, R., Salwiyah, dan Irawati, N. (2016). Perbandingan Kepadatan dan Keanekaragaman Perifiton pada Subtrat Buatan yang Berbeda di Perairan Air Terjun Tinonggoli (Nanga-Nanga) Kota Kendari Sulawesi Tenggara. Jurnal Manajemen Sumber Daya Perairan, 2(1), 71-78.

Nirmalasari, R. (2018). Analisis Kualitas Air Sungai Sebangau Pelabuhan Kereng Bengkiray Berdasarkan Keanekaragaman dan Komposisi Fitoplankton. Jurnal Ilmu Alam dan Lingkungan, 9(17), $48-58$

Pasisingi, N. (2014). Diatom Epilitik sebagai Indikator Kualitas Air di Bagian Hulu Sungai Cileungsi, Bogor [tesis]. Institut Pertanian Bogor.

Pasisingi, N., Pratiwi, N.T.M., dan Krisanti, M. (2014a). The Use of
Trophic Diatom Index to Determine Water Quality in The Upstream of Cileungsi River, West Java. Indonesian Fisheries Research Journal, 20(1), 11-16. http://dx.doi.org/10.15578/ifrj.20.1 .2014.11-16

Pasisingi, N., Pratiwi, N.T.M., dan Krisanti, M. (2014b). Kualitas Perairan Sungai Cileungsi Bagian Hulu Berdasarkan Kondisi FisikKimia. Depik, 3(1), 56-64 https://doi.org/10.13170/depik.3.1. 1376

Pratiwi, N.T.M., Hariyadi, S., dan Kiswari, D.I. (2017). Struktur Komunitas Perifiton Dibagian Hulu Sungai Cisadane, Kawasan Taman Nasional Gunung Halimun Salak, Jawa Barat. Jurnal Biologi Indonesia, 13(2), 289-296. https://doi.org/10.14203/jbi.v13i2. 3403

Prescott GW. (1970). How to Know The Freshwater Algae. Montana (US): Wm. C. Brown Company Publishers.

Rafi'i, M., dan Maulana, F. (2018). Jenis, Keanekaragaman dan Kemelimpahan Makrozoobenthos di Sungai Wangi Desa Banua Rantau Kecamatan Banua Lawas. Jurnal Pendidikan Hayati, 4(2), 94-101. https://doi.org/10.33654/jph.v4i2.4 43

Suryono, T., dan Sudarso, J. (2019). Hubungan Komposisi dan Kelimpahan Perifiton dengan Kualitas Air di Sungai dan Danau Oxbow di Palangka Raya pada Kondisi Air Dangkal. LIMNOTEK Perairan Darat Tropis di Indonesia, 26(1), 2338.http://dx.doi.org./10.14203/limn otek.v26i1.192 
Wahyuni, I.S., dan Rosanti, D. (2016). Keanekaragaman Fitoplankton di Kolam Retensi Kambang Iwak Kota Palembang. Jurnal Sainmatika, 13(2), 48-57. http://dx.doi.org/10.31851/sainmati ka.v13i2.1035

Yuniarno, H.A., Ruswahyuni, dan Suryanto, A. (2015). Kelimpahan Perifiton pada Karang Masif dan Bercabang di Perairan Pulau Panjang Jepara. Diponegoro Journal of Maquares, 4(4), 99108.

https://doi.org/10.14710/marj.v4i4. 9778

Zuardi, S.H., dan Wardhana, W. (2018). Struktur Komunitas Epifiton pada Tanaman Utricularia sp. di Situ Alam FMIPA Universitas Indonesia, Depok, Jawa Barat. Proceeding of Biology Education, 2(1), 59-66. https://doi.org/https://doi.org/10.21 009/pbe.2-1.8 
